Pacific Journal of Mathematics

A CHARACTERIZATION OF THE WEIGHTS IN A DIVIDED 


\title{
A CHARACTERIZATION OF THE WEIGHTS IN A DIVIDED DIFFERENCE
}

\author{
D. J. Newman and T. J. Rivlin
}

Given points $x_{0}, x_{1}, \cdots, x_{n}$ of the real line which satisfy $x_{0}<$ $x_{1}<\cdots<x_{n}$ put

$$
w(u)=\left(u-x_{0}\right) \cdots\left(u-x_{n}\right) .
$$

If function values $f\left(x_{0}\right), \cdots, f\left(x_{n}\right)$ are given, the divided difference of $f$ with respect to $x_{0}, \cdots, x_{n}$ may be defined by

$$
f\left(x_{0}, \cdots, x_{n}\right)=\sum_{i=0}^{n} \frac{f\left(x_{i}\right)}{w^{\prime}\left(x_{i}\right)} .
$$

If we put

$$
a_{i}=\frac{1}{w^{\prime}\left(x_{i}\right)}, \quad i=0, \cdots, n
$$

we call $a_{0}, \cdots, a_{n}$ the weights of the divided difference. Our problem is to characterize the vectors $a:\left(a_{0}, \cdots, a_{n}\right)$ which satisfy (2) for some $x:\left(x_{0}, \cdots, x_{n}\right)$ and to show that such $a$ correspond to an essentially unique $x$.

Note that

$$
\begin{gathered}
w^{\prime}\left(x_{i}\right)=\left(x_{i}-x_{0}\right) \cdots\left(x_{i}-x_{i-1}\right)\left(x_{i}-x_{i+1}\right) \cdots\left(x_{i}-x_{n}\right), \\
i=0, \cdots, n,
\end{gathered}
$$

so that translating the point $x$ leaves $a$ unchanged. Therefore we add the further (normalizing) assumption that $x_{0}=0$. We can now state our result.

THEOREM. If $n>0$ (2) holds for unique $x_{0}, \cdots, x_{n}$ satisfying $0=x_{0}<x_{1}<\cdots<x_{n}$ if, and only if,

(i ) $(-1)^{n-i} a_{i}>0, i=0, \cdots, n$

(ii) $\sum_{i=0}^{n} a_{i}=0$

and

(iii) $(-1)^{n-j} \sum_{i=j}^{n} a_{i}>0, j=1, \cdots, n$.

Note that this theorem may be viewed as characterizing the slopes at its zeros of a polynomial $w(u)=u\left(u-x_{1}\right) \cdots\left(u-x_{n}\right)$.

Proof. (a) Suppose $x_{0}, \cdots, x_{n}$ satisfying $0=x_{0}<x_{1}<\cdots<x_{n}$ are given. (i) follows immediately from (3). Since $f\left(x_{0}, \cdots, x_{n}\right)=0$ if $f$ is a polynomial of degree $<n$, taking $f \equiv 1$ in (1) yields (ii). As 
for (iii) consider the fundamental polynomials of Lagrangian interpolation in $x_{0}, \cdots, x_{n}$

$$
l_{i}(x)=\frac{w(x)}{\left(x-x_{i}\right) w^{\prime}\left(x_{i}\right)}, \quad i=0, \cdots, n .
$$

Put

$$
p_{j}(x)=\sum_{i=0}^{j} l_{i}(x), \quad j=0, \cdots, n-1 .
$$

Then $p_{j}\left(x_{i}\right)=1, i=0, \cdots, j, p_{j}\left(x_{i}\right)=0, i=j+1, \cdots, n$ and so $p_{j}$ is of positive degree. If $c_{j}$ is the coefficient of $x^{n}$ in $p_{j}$ then

$$
c_{j}=\sum_{i=0}^{j} a_{i}
$$

Now $p_{j}^{\prime}$ is of degree at mast $n-1$ and by Rolle's theorem has $j$ zeros in $\left(x_{0}, x_{j}\right)$ and $n-1-j$ zeros in $\left(x_{j+1}, x_{n}\right)$ which accounts for all its zeros. Thus $c_{j} \neq 0$ and, since the behavior of $p_{j}(x)$ at $\infty$ determines the sign of $c_{j}$, this sign is that of $p_{j}^{\prime}\left(x_{n}\right)$. We proceed to determine that sign. To this end note that $p_{j}^{\prime}\left(x_{j}\right) \neq 0$. If $p_{j}^{\prime}\left(x_{j}\right)>0$ then since $p_{j}\left(x_{j}\right)=1$ and $p_{j}\left(x_{j+1}\right)=0, p_{j}^{\prime}(x)$ has a zero in $\left(x_{j}, x_{j+1}\right)$, implying that $p_{j}=0$, and contradicting the fact that $p_{j}$ is of positive degree. Thus $p_{j}^{\prime}\left(x_{j}\right)<0$ which implies that $p_{j}^{\prime}\left(x_{j+1}\right)<0$ and hence that $p_{j}^{\prime}\left(x_{n}\right)$ has the sign $(-1)^{n-j}$. We have shown that

$$
(-1)^{n-j} \sum_{i=0}^{j} a_{i}>0, \quad j=0, \cdots, n-1,
$$

and hence for $j=0, \cdots, n-1$

$$
(-1)^{n-j} \sum_{i=j+1}^{n} a_{i}=(-1)^{n-j}\left(\sum_{i=0}^{n} a_{i}-\sum_{i=0}^{j} a_{i}\right)<0
$$

in view of (ii), from which (iii) follows.

(b) We prove next that for each $a$ satisfying (i), (ii), (iii) there exist unique $x_{0}, \cdots, x_{n}$ satisfying $0=x_{0}<\cdots<x_{n}$ such that (2) holds.

Let $K$ denote the convex set in $R^{n}$ defined by the inequalities

$$
(-1)^{n-i} t_{i}>0, \quad i=1, \cdots, n,
$$

and

$$
(-1)^{n-j} \sum_{i=j}^{n} t_{i}>0, \quad j=1, \cdots, n .
$$

In view of (i) and (iii) $K$ is not empty. Let $S$ be the convex set of all $\left(x_{1}, \cdots, x_{n}\right) \in R^{n}$ such that $0<x_{1}<x_{2}<\cdots<x_{n}$. Let $\phi$ be the continuous mapping of $S$ into $K$ defined by 


$$
\phi:\left(x_{1}, \cdots, x_{n}\right) \longrightarrow\left(a_{1}, \cdots, a_{n}\right)
$$

where the $a_{i}$ are as defined in (2) with $x_{0}=0$. We intend to show that $\phi$ is a grobal homeomorphism of $S$ onto $K$. If this were so then given $a_{0}, \cdots, a_{n}$ satisfying (i), (ii) and (iii), $\left(a_{1}, \cdots, a_{n}\right)$ is in $K$ and its unique preimage $\left(x_{1}, \cdots, x_{n}\right)$ satisfies $0=x_{0}<x_{1}<\cdots<x_{n}$ and $a_{i}=\left(w^{\prime}\left(x_{i}\right)\right)^{-1}, i=1, \cdots, n$. But then in view of (ii)

$$
a_{0}=-\sum_{i=1}^{n} a_{i}=-\sum_{i=1}^{n} \frac{1}{w^{\prime}\left(x_{i}\right)}=\frac{1}{w^{\prime}\left(x_{0}\right)},
$$

and the proof of the theorem would be complete. It remains, therefore, to show that $\phi$ is a homeomorphism of $S$ onto $K$.

We begin by showing that the Jacobian matrix of $\phi, J(\phi)$ is nonsingular in $S$. Given $0=x_{0}<x_{1}<\cdots<x_{n}$ the divided difference $f\left(x_{0}, \cdots, x_{n}\right)=0$ if $f$ is a polynominal of degree at most $n-1$ while if $f=x^{n}, f\left(x_{0}, \cdots, x_{n}\right)=1$. If we take $f$ to be $x, x^{2}, \cdots, x^{n}$ successively we thus obtain

$$
\begin{aligned}
& \sum_{i=1}^{n} a_{i} x_{i}^{j}=0, \quad j=1, \cdots, n-1, \\
& \sum_{i=1}^{n} a_{i} x_{i}^{n}=1 .
\end{aligned}
$$

Partial differentiation with respect to $x_{i}$ gives

$$
\left(\begin{array}{cccc}
x_{1} & x_{2} & \cdots & x_{n} \\
x_{1}^{2} & x_{2}^{2} & \cdots & x_{n}^{2} \\
\vdots & & \\
x_{1}^{n} & x_{2}^{n} & \cdots & x_{n}^{n}
\end{array}\right)\left(\begin{array}{c}
\frac{\partial a_{1}}{\partial x_{i}} \\
\vdots \\
\frac{\partial a_{n}}{\partial x_{i}}
\end{array}\right)+\left(\begin{array}{c}
1 \\
2 x_{i} \\
3 x_{i}^{2} \\
\vdots \\
n x_{i}^{n-1}
\end{array}\right) a_{i}=0
$$

so that,

$$
A J(\phi)+B:=\left(\begin{array}{cc}
x_{1} & x_{2} \cdots x_{n} \\
\vdots & \\
x_{1}^{n} & x_{2}^{n} \cdots x_{n}^{n}
\end{array}\right) J(\phi)+\left(\begin{array}{ccc}
a_{1} & \cdots & a_{n} \\
2 a_{1} x_{1} & 2 a_{n} x_{n} \\
\vdots & \vdots \\
n a_{1} x_{1}^{n-1} & n a_{n} x_{n}^{n-1}
\end{array}\right)=0 .
$$

Since $A$ and $B$ are nonzero multiplies of the Vandermonde matrix they are nonsingular and so, therefore, is $J(\phi)$.

Next we show that $\phi$ maps the boundary of $S$ (which includes the point at infinity) into the boundary of $K$ (which includes the point at infinity) in the sense that if a sequence of points of $S$ has a limit point in $\partial S$ then the image sequence under $\phi$ has its limit points in $\partial K$. The boundary points of $S$ arise either from coalescence 
of coordinates or coordinates tending to zero or infinity, or combinations of these. (3) reveals that if 2 or more coordinates coalesce with $x_{i}$ and stay bounded away from 0 and $\infty$ then $w^{\prime}\left(x_{i}\right) \rightarrow 0$ and hence $a_{i} \rightarrow \infty$. If $x_{1} \rightarrow 0$ and $w^{\prime}\left(x_{1}\right) \rightarrow 0$, or $x_{n} \rightarrow \infty$ and $w^{\prime}\left(x_{n}\right) \rightarrow \infty$, boundary goes to boundary. The only remaining possibility is that $x_{1} \rightarrow 0$ and $x_{n} \rightarrow \infty$ in such a way that $\left\{\left|w^{\prime}\left(x_{i}\right)\right|\right\}, i=1, \cdots, n$ stays bounded away from 0 and $\infty$. This can only happen if for some $j$ satisfying $2 \leqq j \leqq n-1$ we have $x_{j-1} \rightarrow 0$ and $x_{j} \rightarrow \infty$. But in this case put $p(x)=x\left(x-x_{1}\right) \cdots\left(x-x_{j-1}\right)$ and $q(x)=\left(x-x_{j}\right) \cdots\left(x-x_{n}\right)$. Then on the one hand eventually

$$
\frac{1}{2 \pi i} \int_{|z|=1} \frac{d z}{p(z) q(z)}=\sum_{i=0}^{j-1} \frac{1}{w^{\prime}\left(x_{i}\right)}
$$

by the calculus of residues, while on the other the integral tends to zero since $|q| \rightarrow \infty$. Thus

$$
\lim \sum_{i=0}^{j-1} a_{i}=\lim \sum_{i=j}^{n} a_{i}=0,
$$

so that the image sequence again tends to the boundary of $K$.

We are now in a position to show that $\phi$ maps $S$ onto $K$. Since $J(\phi)$ is nonsingular, $\phi(S)$ is open in $K$. Let $w \in \phi(S)^{\circ} \cap K$, we claim that some neighborhood of $w$ lies in $\phi(S)^{c} \cap K$. Otherwise there is a sequence $w_{i}=\phi\left(z_{i}\right)$ with $w_{i} \rightarrow w$. If the $z_{i}$ went to the boundary, $\partial S$, then the $\phi\left(z_{i}\right)\left(=w_{i}\right)$ would converge to the boundary $\partial K$ and we would have $w \in \partial K$. This contradicts our assumption and we conclude, indeed, that $\phi(S)^{c} \cap K$ is open. Thus $K=\left(\phi(S)^{c} \cap K\right) \cup(\phi(S) \cap K)$ is the union of two disjoint open sets. $K$, being convex, is certainly connected, however, and so we are forced to the conclusion that $\phi(S) \cap K=K$ or $\phi(S)=K$.

Thus, to sum up, we have shown that $\phi$ is a continuous map of convex $S$ onto convex $K$ which is locally one-to-one and takes the boundary of $S$ into the boundary of $K$.

Next we show, following Favard (Cf. J. Favard, Cours d'Analyse de l'École Polytechnique, Vol. I, Paris, 1960, pp. 295-296.) that there is a fixed integer $k \geqq 1$ such that each point of $K$ has exactly $k$ preimages in $S$.

First we observe that if $t \in K$ then $t=\phi(x)$ cannot hold for infinitely many $x \in S$. For if $t=\phi(x)$ for infinitely many $x \in S$ then the set of such $x$ cannot have a boundary point of $S$ as limit point since $t \in K$ and $\phi$ takes $\partial S$ into $\partial K$. Thus the set of solutions $\{x\}$ has a limit point in $S$ contradicting the fact that $\phi$ is a local homeomorphism.

Suppose that $\bar{t} \in K$ and $x^{(1)}(\bar{t}), \cdots, x^{(s)}(\bar{t})$ are its preimages. The inverse functions $x=\Psi_{1}(t), \cdots, x=\Psi_{s}(t)$ are homeomorphisms of 
some neighborhood of $\bar{t}$, and these neighborhoods have a nonempty intersection. Let $r(\bar{t})$ be the radius of the largest ball centered at $\bar{t}$ in which $\Psi_{1}, \cdots, \Psi_{s}$ are homeomorphisms. It is easy to see that $\left|r\left(t^{(1)}\right)-r\left(t^{(2)}\right)\right| \leqq\left\|t^{(1)}-t^{(2)}\right\|$, hence $r(t)$ is continuous in $K$ and has a positive lower bound on every compact subset of $K$. Now every point $t^{\prime}$ contained in the largest ball of homeomorphy centered at $t$ has at least as many preimages as does $t$, i.e., $s\left(t^{\prime}\right) \geqq s(t)$. On the other hand in the closed ball '\|t-t' $\| \leqq r(t) / 2, r\left(t^{\prime}\right)$ has a positive lower bound, $b$, and if we further restrict $t^{\prime}$ so that $\left\|t-t^{\prime}\right\|<b$ then the largest ball of homeomorphy centered at $t^{\prime}$ contains $t$ so that $s(t) \geqq s\left(t^{\prime}\right)$, hence $s(t)=s\left(t^{\prime}\right)$ and $s(t)$ is a continuous integervalued function of $t$ in the convex set $K$, hence a constant, $k \geqq 1$.

We next conclude the proof of our theorem by exhibiting an explicit $t$ which has a unique pre-image. To this end consider the points

$$
\eta_{j}=-\cos \frac{j \pi}{n}, \quad j=0, \cdots, n,
$$

the extrema of the Chebyshev polynomial of the first kind of degree $n$. An elementary computation yields

$$
\begin{aligned}
f\left(\eta_{0}, \cdots, \eta_{n}\right) & =(-1)^{n} \frac{2^{n-1}}{n}\left(\frac{f\left(\eta_{0}\right)}{2}+\sum_{j=1}^{n-1}(-1)^{j} f\left(\eta_{j}\right)+\frac{(-1)^{n}}{2} f\left(\eta_{n}\right)\right) \\
& =:(-1)^{n} \frac{2^{n-1}}{n} \sum_{j=0}^{n}{ }^{\prime \prime}(-1)^{j} f\left(\eta_{j}\right)
\end{aligned}
$$

and taking $f(u)$ to be $u, u^{2}, \cdots, u^{n-1}$ sucessively yields

$$
\sum_{j=0}^{n}{ }^{\prime \prime}(-1)^{j} \eta_{j}^{i}=0, \quad i=1, \cdots, n-1 .
$$

Suppose $y_{0}<y_{1}<\cdots<y_{n}$ has the property that,

$$
\frac{(-1)^{n}}{W^{\prime}\left(y_{i}\right)}=\frac{(-1)^{n}}{V^{\prime}\left(\eta_{i}\right)}= \begin{cases}\frac{2^{n-1}}{2 n} ; \quad i=0, & \\ \frac{2^{n-1}}{n}(-1)^{i} ; & i=1, \cdots, n-1, \\ \frac{2^{n-1}}{2 n}(-1)^{n} ; & i=n\end{cases}
$$

where $V(u)=\left(u-\eta_{0}\right) \cdots\left(u-\eta_{n}\right), \quad W(u)=\left(u-y_{0}\right) \cdots\left(u-y_{n}\right)$ and we may assume, with no loss of generality, that $y_{0}=-y_{n}$. Then we have

$$
\sum_{j=0}^{n \prime \prime}(-1)^{j} y_{j}^{i}=0, \quad i=1, \cdots, n-1
$$


and if we put

$$
x_{j}=\frac{y_{j}}{y_{n}}=: C y_{j}, \quad j=0, \cdots, n
$$

then

$$
\begin{gathered}
\sum_{i=0}^{n}{ }^{\prime \prime}(-1)^{j} x_{j}^{i}=0, \quad i=1, \cdots, n-1, \\
x_{0}=\eta_{0}=-1 ; \quad x_{n}=\eta_{n}=1
\end{gathered}
$$

and $x_{0}<x_{1}<\cdots<x_{n}$.

Equating the left-hand sides in (6) to the corresponding ones in (8) yields the systems

$$
x_{1}^{i}+\eta_{2}^{i}+\cdots+x_{n-1}^{i}=\eta_{1}^{i}+x_{2}^{i}+\cdots+\eta_{n-1}^{i}, \quad i=1, \cdots, n-1 ;
$$

$n$ even or

$$
x_{1}^{i}+\eta_{2}^{i}+\cdots+\eta_{n-1}^{i}=\eta_{1}^{i}+x_{2}^{i}+\cdots+x_{n-1}^{i}, \quad i=1, \cdots, n-1 ;
$$

$n$ odd. We claim that (9a) or (9b) implies that $\eta_{i}=x_{i}, i=1, \cdots$, $n-1$. To establish this we use the following lemma.

LEMMA. If

$$
\sum_{j=1}^{k} b_{j}^{i}=\sum_{i=1}^{k} c_{j}^{i}, \quad i=1, \cdots, k
$$

and $b_{1}<\cdots<b_{k} ; c_{1}<\cdots<c_{k}$ then $b_{j}=c_{j}, j=1, \cdots, k$.

Proof. Let

$$
S_{i}(b)=\sum_{j=1}^{k} b_{j}^{i}, \quad i=1, \cdots, k .
$$

We assume $S_{i}(b)=S_{i}(c), i=1, \cdots, k$. The elementary symmetric functions $\sigma_{1}(b), \cdots, \sigma_{k}(b)$ are uniquely determined by $S_{1}(b), \cdots, S_{k}(b)$ hence $\sigma_{i}(b)=\sigma_{i}(c), i=1, \cdots, k$. Thus $\left(c_{1}, \cdots, c_{k}\right)$ and $\left(b_{1}, \cdots, b_{k}\right)$ are the complete set of zeros of the same polynomial. Since they are ordered by hypothesis, the lemma follows.

The lemma applied to (9a), say, implies that $x_{1}, \eta_{2}, \cdots, x_{n-1}$ is a rearrangement of $\eta_{1}, x_{2}, \cdots, \eta_{n-1}$. Thus in the sequence $\eta_{1}, \cdots, \eta_{n-1}$, $x_{1}, \cdots, x_{n-1}$ each of $\eta_{1}, \cdots, \eta_{n-1}$ appears twice. But then the monotonicity of the vectors $\eta$ and $x$ implies that $x_{j}=\eta_{j}, j=1, \cdots, n-1$. The same argument prevails if $(9 \mathrm{~b})$ holds. Thus we have shown that

$$
y_{j}=\frac{\eta_{j}}{C}, \quad j=0, \cdots, n
$$


But, in view of the analogue of (3), (7) implies that $C=1$.

We have established that the weight vector

$$
(-1)^{n} \frac{2^{n-1}}{n}\left(\frac{1}{2},-1,+1, \cdots,(-1)^{n-1}, \frac{(-1)^{n}}{2}\right)
$$

corresponds uniquely to the (normalized) points

$$
1+\eta_{j}, \quad j=0, \cdots, n
$$

and so we may conclude that $\left(\left(1+\eta_{1}\right), \cdots,\left(1+\eta_{n}\right)\right)$ is the unique element of $S$ whose image under $\phi$ is

$$
(-1)^{n} \frac{2^{n-1}}{n}\left(-1,1, \cdots,(-1)^{n-1}, \frac{(-1)^{n}}{2}\right) \text {. }
$$

This completes the proof of the theorem.

Postscript. I. J. Schoenberg reports (Cardinal Spline Interpolation, Vol. 12, Regional Conference Series in Applied Mathematics, Philadelphia, 1973, p. 9) that S. Karlin told him that he had solved the problem of characterizing the weights in a divided difference. Professor Karlin has confirmed this in a phone conversation with one of us, but not wishing to publish his solution suggested that we present ours.

Received June 13, 1979.

Temple University

Philadelphia, PA 19122

AND

IBM

Box 218

YoRKTOWn Heights, NY 10598 



\title{
PACIFIC JOURNAL OF MATHEMATICS
}

\section{EDITORS}

\author{
DoNALD BABBITT (Managing Editor) \\ University of California \\ Los Angeles, CA 90024 \\ Hugo RossI \\ University of Utah \\ Salt Lake City, UT 84112 \\ C. C. MOORE and ANDrew OGG \\ University of California \\ Berkeley, CA 94720
}

J. DugundJI

Department of Mathematics

University of Southern California

Los Angeles, CA 90007

R. FINN and J. MILGRAM

Stanford University

Stanford, CA 94305

\section{ASSOCIATE EDITORS}
R. Arens
E. F. BeCKenbaCH
B. H. NeumanN
F. WOLF
K. YoSHIDA

\section{SUPPORTING INSTITUTIONS}

UNIVERSITY OF ARIZONA

UNIVERSITY OF BRITISH COLUMBIA

CALIFORNIA INSTITUTE OF TECHNOLOGY

UNIVERSITY OF CALIFORNIA

MONTANA STATE UNIVERSITY

UNIVERSITY OF NEVADA, RENO

NEW MEXICO STATE UNIVERSITY

OREGON STATE UNIVERSITY

\author{
UNIVERSITY OF OREGON \\ UNIVERSITY OF SOUTHERN CALIFORNIA \\ STANFORD UNIVERSITY \\ UNIVERSITY OF HAWAII \\ UNIVERSITY OF TOKYO \\ UNIVERSITY OF UTAH \\ WASHINGTON STATE UNIVERSITY \\ UNIVERSITY OF WASHINGTON
}

The Supporting Institutions listed above contribute to the cost of publication of this Journal, but they are not owners or publishers and have no responsibility for its content or policies.

Mathematical papers intended for publication in the Pacific Journal of Mathematics should be in typed form or offset-reproduced, (not dittoed), double spaced with large margins. Please do not use built up fractions in the text of the manuscript. However, you may use them in the displayed equations. Underline Greek letters in red, German in green, and script in blue. The first paragraph or two must be capable of being used separately as a synopsis of the entire paper. Please propose a heading for the odd numbered pages of less than 35 characters. Manuscripts, in triplicate, may be sent to any one of the editors. Please classify according to the scheme of Math. Reviews, Index to Vol. 39. Supply name and address of author to whom proofs should be sent. All other communications should be addressed to the managing editor, or Elaine Barth, University of California, Los Angeles, California, 90024.

50 reprints to each author are provided free for each article, only if page charges have been substantially paid. Additional copies may be obtained at cost in multiples of 50 .

The Pacific Journal of Mathematics is issued monthly as of January 1966. Regular subscription rate: $\$ 102.00$ a year $(6$ Vols., 12 issues). Special rate: $\$ 51.00$ a year to individual members of supporting institutions.

Subscriptions, orders for numbers issued in the last three calendar years, and changes of address shoud be sent to Pacific Journal of Mathematics, P.O. Box 969, Carmel Valley, CA 93924, U.S.A Old back numbers obtainable from Kraus Periodicals Co., Route 100, Millwood, NY 10546.

\section{PUBLISHED BY PACIFIC JOURNAL OF MATHEMATICS, A NON-PROFIT CORPORATION}

Printed at Kokusai Bunken Insatsusha (International Academic Printing Co., Ltd.). 8-8, 3-chome, Takadanobaba, Shinjuku-ku, Tokyo 160, Japan. 


\section{Pacific Journal of Mathematics}

Vol. 93, No. $2 \quad$ April, 1981

Ilya Eugene Blum and Srinivasa Swaminathan, Continuous selections and

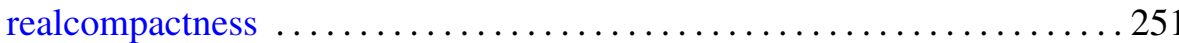

Lawrence James Brenton, Differentiably $k$-normal analytic spaces and extensions of holomorphic differential forms $\ldots \ldots \ldots \ldots \ldots \ldots \ldots 261$

Jo-Ann Deborah Cohen, Topologies on the ring of integers of a global field ................................................... 269

Robert Jay Daverman, Detecting the disjoint disks property $\ldots \ldots \ldots \ldots 277$

Edmund H. Feller, Rings where the annihilators of $\alpha$-critical modules are prime ideals ....................................... 299

Richard Elam Heisey and Henryk Torunczyk, On the topology of direct

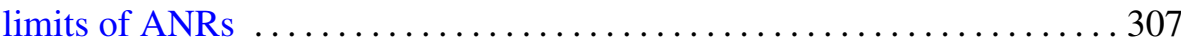

Gerald William Johnson and David Lee Skoug, Notes on the Feynman

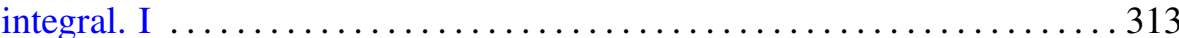

Michael S. Keane and Stuart Jay Sidney, Distinguishing a plane curve

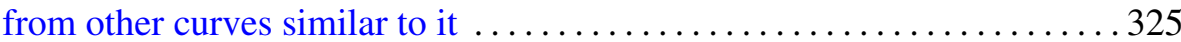

Leonid A. Luxemburg, On compact metric spaces with noncoinciding

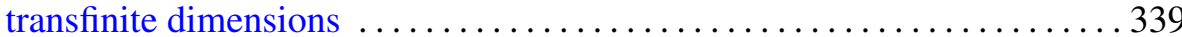

Chun Ming Ma, A uniqueness theorem for Navier-Stokes equations . . . . . . 387

Donald J. Newman and Theodore Joseph Rivlin, A characterization of the weights in a divided difference . . . . . . . . . . . . . . . . . . . 407

Marc Aristide Rieffel, $C^{*}$-algebras associated with irrational rotations $\ldots .415$

Kichi-Suke Saito, Invariant subspaces for finite maximal subdiagonal algebras

Frederic W. Shultz, Dual maps of Jordan homomorphisms and ${ }^{*}$-homomorphisms between $C^{*}$-algebras $\ldots \ldots \ldots \ldots$

Vsevolod Alekseevich Solonnikov, On the solvability of boundary and initial-boundary value problems for the Navier-Stokes system in domains with noncompact boundaries

Tavan Thomas Trent, New conditions for subnormality

L. E. Ward, Extending Whitney maps ..................

Leslie Wilson, Jets with regular zeros

Sergio Eduardo Zarantonello, The sheaf of $H^{p}$-functions in product 